\title{
Runoff variations in the Yangtze River Basin and sub-basins based on GRACE, hydrological models, and in-situ data
}

\author{
WeiLong Rao, and WenKe Sun* \\ University of Chinese Academy of Sciences, Beijing 100049, China
}

Key Points:

- Runoff variations in the Yangtze River Basin and its sub-basins were estimated based on GRACE data and hydrological models.

- The contribution of human water resource consumption to water budget closure was considered.

- The mainstream hydrological model's application effect in the Yangtze River Basin was evaluated.

Citation: Rao, W. L., and Sun, W. K. (2022). Runoff variations in the Yangtze River Basin and sub-basins based on GRACE, hydrological models, and in-situ data. Earth Planet. Phys., 6(3), 228-240. http://doi.org/10.26464/epp2022021

\begin{abstract}
Water budget closure is a method used to study the balance of basin water storage and the dynamics of relevant hydrological components (e.g., precipitation, evapotranspiration, and runoff). When water budget closure is connected with terrestrial water storage change (TWSC) estimated from Gravity Recovery and Climate Experiment (GRACE) data, variations in basin runoff can be understood comprehensively. In this study, total runoff variations in the Yangtze River Basin (YRB) and its sub-basins are examined in detail based on the water budget closure equation. We compare and combine mainstream precipitation and evapotranspiration models to determine the best estimate of precipitation minus evapotranspiration. In addition, we consider human water consumption, which has been neglected in earlier studies, and discuss its impact. To evaluate the effectiveness and accuracy of the combined hydrological models in estimating subsurface runoff, we collect discharge variations derived from in situ observations in the YRB and its sub-basins and compare these data with the models' final estimated runoff variations. The estimated runoff variations suggest that runoff over the YRB has been increasing, especially in the lower sub-basins and in the post-monsoon season, and is accompanied by apparent terrestrial water loss.
\end{abstract}

Keywords: runoff; discharge; Yangtze River Basin; water budget closure; GRACE

\section{Introduction}

The Yangtze River, which is the longest river in China and the third-longest river in the world, originates on the Tibetan Plateau and flows approximately $6300 \mathrm{~km}$ eastwards to the East China Sea (Wang GJ et al., 2008). The Yangtze River Basin (YRB) has a drainage area of over 1.8 million $\mathrm{km}^{2}$ and directly feeds approximately one-third of China's total population with rich terrestrial water resources (Zhu M et al., 2020). River discharge variation has been measured traditionally by stream gauging. The average discharge rate between 2003 and 2016 at the Datong station, estimated from data in the Chinese River Sediment Bulletin, was $27,000 \mathrm{~m}^{3} / \mathrm{s}$. This discharge value represents the volume of water that passes through a given cross-section per unit time.

Discharge gauging is essential for water resource management, climate studies, and flood management (Sichangi et al., 2016). However, these in situ observations are point measurements and are not always representative of what is occurring over large spatial domains (Famiglietti et al., 2008). More importantly, total basin runoff includes surface river discharge and subsurface runoff

Correspondence to: W. K. Sun, sunw@ucas.ac.cn

Received 05 DEC 2021; Accepted 25 JAN 2022.

Accepted article online 11 MAR 2022.

(C) 2022 by Earth and Planetary Physics.
(Syed et al., 2005). The YRB discharge flux is not clearly distinguished from the basin's runoff, and the subsurface runoff estimates show large differences from the results of other approaches (Zhang J et al., 2011; Niu GY et al., 2011; Lv MZ et al., 2021). Large differences exist among different hydrological models because no direct measurements of subsurface runoff have been available. Therefore, by relying only on hydrological station observational data and hydrological models, our knowledge of basin runoff has remained seriously incomplete.

Most recent studies of basin-scale water budget closure (Syed et al., 2005; Long D et al., 2014; Lv MX et al., 2017; Li Q et al., 2018; Chen JL et al., 2020; Fang J et al., 2021; Shen Y et al., 2022; Zhang L and Sun WK, 2022) have benefitted from the Gravity Recovery and Climate Experiment (GRACE) mission. The GRACE-derived terrestrial water storage change (TWSC) captures variations in residual water storage, including in natural water supply and loss; TWSC data are thus a perfect fit for water budget studies (Rodell and Famiglietti, 1999). When the water budget closure method is combined with TWSC results, it becomes possible to balance the dynamics of basin runoff and TWSC data in a single equation, because the main factors in the water budget closure equation are precipitation, evapotranspiration, runoff, and TWSC. Thus, precise runoff variation information can be obtained from this water budget closure equation. However, it remains challenging to 
achieve a balance without considering human water use in estimating other water budget terms (Lv MZ et al., 2021). In fact, the contribution of human water consumption (e.g., irrigation and water diversion projects) has been ignored in this equation (Long D et al., 2015; Lv MX et al., 2016) and thus neglected in previous studies (Syed et al., 2009; Xue BL et al., 2013; Ferreira et al., 2013; Chen YT et al., 2019; Wang HS et al., 2022). Therefore, on the one hand, neglected human water consumption increases uncertainties in the estimates of basin runoff. On the other hand, estimates of basin runoff have been limited by uncertainties in the data and processing algorithms of hydrological models that have depended on various satellite observation. Penatti et al. (2015) quantified the hydrological dynamics of the world's largest continuous wetland; however, the estimated runoff was greatly overestimated, due mainly to underestimation of evapotranspiration. Similarly, Oliveira et al. (2014) assessed the water balance of the Brazilian Cerrado based on remotely sensed estimates and found that runoff was overestimated, due mainly to overestimation of rainfall. In short, the accuracy of basin runoff, estimated from the water budget closure method, is known to have been seriously impaired by limitations of hydrological models and their neglect of human water consumption.

The water budget closure equation used in this study of runoff variations in the YRB and its sub-basins therefore adds previouslyneglected human water consumption data to data from GRACE, from in-situ observations, and from improved hydrological models in hopes of achieving a more detailed and accurate understanding of total regional water inputs and outputs. Figure 1 shows the distribution of hydrological stations and the division of sub-basins of the YRB. River discharge measurements from hydrological stations were used as references for estimating runoff. Statistical analysis between four sets of P and ET models allows us to have a specific confidence interval of precipitation-evapotranspiration (P minus ET). Spatial and seasonal variations in the entire basin and its sub-basins were researched. In addition, discharge is distinguished from runoff to understand the contribution of subsurface runoff.

The rest of this paper is structured as follows. Section 2 describes the datasets and methods used in the study. Section 3 presents the variations of all components in the water budget closure equation and estimations of runoff and subsurface runoff. Discussion and conclusions appear in Section 4.

\section{Data and Methods}

To estimate runoff variation in the YRB based on the water budget closure method, the required inputs include precipitation, evapotranspiration, and water storage. This study uses data from evapotranspiration models and GRACE observations, as have previous investigations, but adds in situ precipitation data, river discharge measurements, human water consumption data, and extreme climate indices.

\subsection{Hydrological Models and In-situ Data}

Currently, many global precipitation $(P)$ data and evapotranspiration (ET) models are available (gauge-based, satellite-related, and reanalysis datasets) from different organizations (Sun QH et al., 2018). The mainstream land surface models (Zhang D et al., 2016; Li Q et al., 2018; Jing WL et al., 2019; Chen JL et al., 2020; Martin et al., 2020; Rao WL and Sun WK, 2021, 2022; Xing LL et al., 2021) include the Global Land Data Assimilation System (GLDAS), Global Precipitation Climatology Project (GPCP), GLEAM (Global Land Evaporation Amsterdam Model), and ERA5 models. One reason these models have been popular is that they merge various satellite-based estimates over both ocean and land with gauge meas-

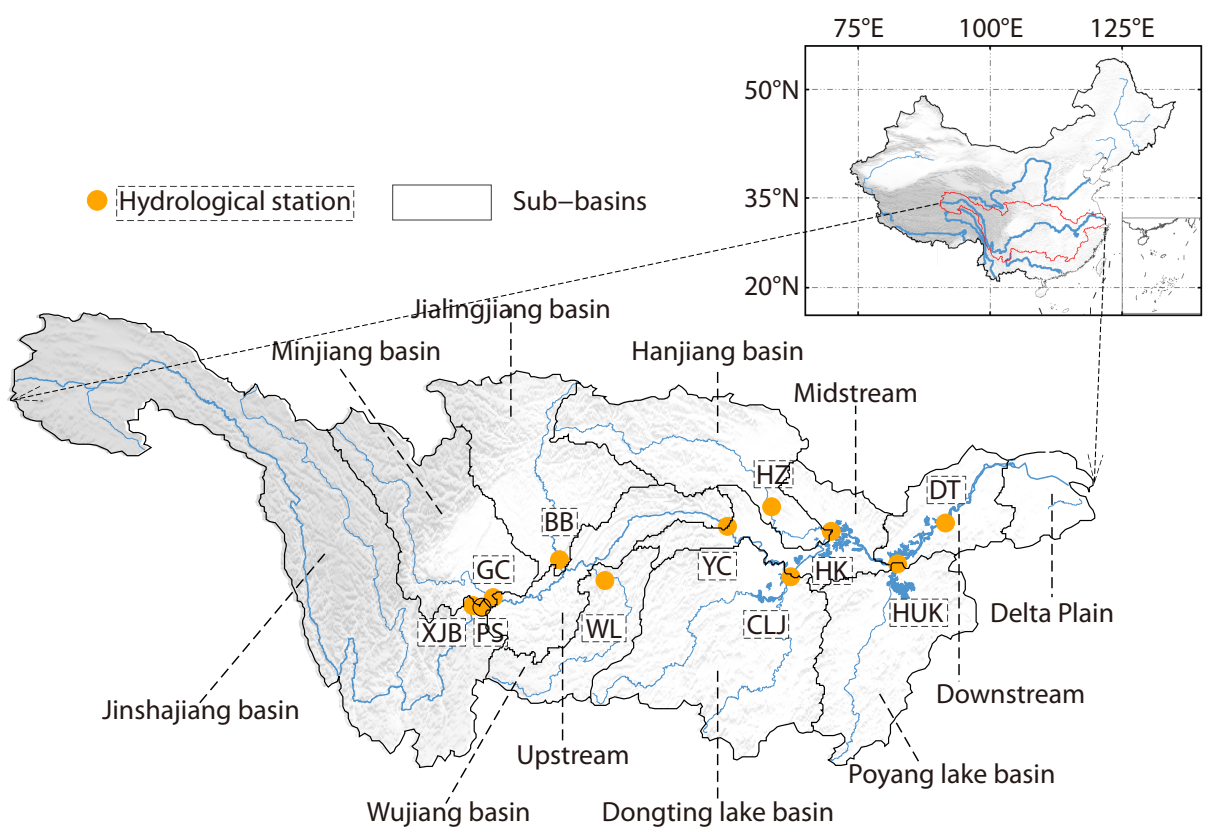

Figure 1. The geographic location of the YRB in China and the division of its sub-basins. The orange dots represent hydrological observatory stations. Abbreviations: XJB: Xiangjiaba; PS: Pingshan; GC: Gaochang; BB: Beibei; WL: Wulong; YC: Yichang; HZ: Huangzhuang; CLJ: Chenglingji; HK: Hankou; HUK: Hukou; and DT: Datong. 
urements. For instance, the GPCP monthly precipitation analysis, one of the most popular products used in climate studies, merges gauge observations with low-orbit satellite microwave data and geosynchronous orbit satellite infrared data (Adler et al., 2003). The other reason is that these models provide users with high-resolution globally gridded data under different time resolutions. The application effect of these models in YRB can be evaluated after being compared with independent in situ data and also can be analyzed based on the water budget closure study.

In this study, we have used four sets of monthly $P$ data from the CLM, NOAH, ERA5, and GPCP, collected during the period from January 2003 to December 2016. CLM and NOAH are two widely used sub-models in the second version of GLDAS (Huang $Y$ et al., 2013; Anderson et al., 2015; Xu XF et al., 2020); the other two submodels are the variable infiltration capacity model and the mosaic model (Rodell et al., 2004). ERA5 is the latest generation (5th) of the ECMWF reanalysis system developed through the Copernicus Climate Change Service; the native spatial resolution of the ERA5 reanalysis dataset is $9 \mathrm{~km}$ (Hersbach et al., 2020). The new version 2.3 of the GPCP precipitation model includes corrections and improvements for years after 2002 (Adler et al., 2018). Monthly $P$ data from the above models were applied in this study after assessing the consistency between the models and the in situ data. The gridded products of these models at spatial resolutions of $1^{\circ} \times 1^{\circ}, 1^{\circ} \times 1^{\circ}, 0.1^{\circ} \times 0.1^{\circ}$, and $2.5^{\circ} \times 2.5^{\circ}$ for CLM, NOAH, ERA5, and GPCP, respectively were resampled to $0.1^{\circ} \times 0.1^{\circ}$ using the arithmetic mean method. In addition, the high-resolution meteorological forcing dataset CMFD (He J et al., 2020) was applied to assess the accuracy of the hydrological models.

Similarly, we used four sets of ET data from CLM, NOAH, ERA5, and GLEAM. GLEAM v3.5a is a global dataset spanning 41 years, from 1980 to 2020, based on satellite and reanalysis data (Martens et al., 2017). ET gridded products' time and spatial resolutions are the same as the corresponding P products; GLEAM ET data were thus chosen to have a spatial resolution of $0.25^{\circ}$.

In situ observations of annual discharge amounts collected at 11 hydrological observatory stations (Xiangjiaba, Pingshan, Gaochang, Beibei, Wulong, Yichang, Huangzhuang, Chenglingji, Hankou, Hukou, and Datong) and reported to the Ministry of Water Resources of China, were obtained for this study from the annual Chinese River Sediment Bulletin (Chinese edition). These 11 hydrological stations are the main control stations of the subbasins of the YRB. The spatial distribution of the hydrological stations in the YRB is shown in Figure 1.

Statistical data describing annual water use and consumption of all provinces in China are reported in the Water Resources Bulletin of each province. We collected total annual water use and consumption amounts and the ratios of agriculture, industry, and domestic consumption to total water consumption from 2003 to 2016 in 13 provinces (Jiangsu, Zhejiang, Anhui, Henan, Hubei, Jiangxi, Hunan, Guizhou, Chongqing, Shanxi, Gansu, Qinghai and Sichuan) from each province's annual Water Resources Bulletin.

\subsection{GRACE Data and Data Processing}

Monthly GRACE spherical harmonic coefficients from the RL06 time-variable gravity model are provided by the University of Texas Center for Space Research (CSR), the Jet Propulsion Laboratory (JPL), and the German Research Center for Geosciences (GFZ). The mean solution of these three models was used in this study to cover the 2003-2017 period. Due to the inaccuracy of the GRACE satellite's low degree term coefficients and the lack of a geocenter term coefficient, it is necessary to supplement or replace the GRACE SHs with data from satellite laser-ranging (SLR) (Swenson et al., 2008; Sun $Y$ et al., 2016; Cheng M and Ries, 2017). The degree-1 coefficients were added back, and the degree- 2 terms were replaced with satellite laser-ranging observations. The Glacier Isostatic Adjustment (GIA) effect on the global gravity field should not be neglected and is corrected by the ICE-6G-D model (Peltier et al., 2018).

The terrestrial water storage anomaly (TWSA) derived from GRACE exhibits signal leakage due to data processing filtering and truncation. The forward modeling method (Chen JL et al., 2014) has proven to be effective in reducing the known leakage bias in GRACE estimates of regional mass changes (Chen JL et al., 2016; Chang $L$ and Sun WK, 2021). The major advantage of the forward modeling method is that it is dependent on GRACE data and requires no a priori information (Chen JL et al., 2016). In the forward modeling method, iterative numerical simulations are used to reconstruct a "true" mass change field that best matches the GRACE-observed mass change, after repeating the same data-processing procedures applied to GRACE data (Chen JL et al., 2016). In order to recover the real mass change series of the YRB, monthly "true" mass change reconstruction will be realized. The coefficient relation between the monthly reconstructed "true" mass change value and the corresponding GRACE-observed one can be represented by their ratio, which is called the "factor" in this study.

GRACE-derived TWSA is monthly average information, and time gaps between two released monthly TWSAs are not uniform. Some researchers have tried to fill the gaps using the dynamic interpolation method, redefining the epoch of each month as the exact middle of the month (Chen JL et al., 2020). However, the dynamic interpolation method contains strong constraint information (time series only include seasonal and trend variations). The estimated TWSC was directly determined by fitted results rather than actual TWSA because the anomaly and long-period variation are not considered. Typically, the mid-points of the monthly GRACE observed period are about the middle of the month. Therefore, the more direct and simple method was applied in our study, and the monthly TWSC was estimated from the difference between two consecutive terrestrial water storage totals.

\subsection{Methods}

When the water budget closure equation is used to estimate runoff for the YRB, the equation is usually given (Chen YT et al., 2019; Chen JL et al., 2020) as:

$$
R=P-E T-\mathrm{d} S / \mathrm{d} t,
$$

where $R, P$, and $E T$ are the monthly runoff, precipitation, and evapotranspiration, respectively, and $\mathrm{dS} / \mathrm{d} t$ represents the monthly terrestrial water storage change (Long D et al., 2014; Lv MX et al., 2017), which can be expressed as: 


$$
\mathrm{d} S / \mathrm{d} t=S_{i+1}-S_{i}
$$

in which $S_{i}$ is the terrestrial water storage anomaly (TWSA) for month $i$. In this study, the uniform unit is $\mathrm{cm} / \mathrm{month}$.

Human interventions (e.g., irrigation and water diversion projects) affect the terrestrial hydrological cycle and have received little attention in water budget closure analysis (Lv MX et al., 2019). Strictly speaking, the runoff estimation equation should be expressed as:

$$
R=P-E T-C-\mathrm{d} S / \mathrm{d} t
$$

in which, $C$ represents the human interventions. Therefore, based on the above equations, the runoff variation in the YRB can be estimated based on P, ET, GRACE and water consumption data.

Before we estimate the runoff variation, a statistical analysis of the $P$ and ET models should be conducted. The coefficient of determination $\left(R^{2}\right)$ is a statistical measurement that examines differences in two variables to assess how strong the linear relationship between those variables is. The coefficient of determination can be expressed as Equation (4):

$$
R^{2}=1-\frac{\sum\left(\hat{y}_{i}-\bar{y}\right)^{2}}{\sum\left(y_{i}-\bar{y}\right)^{2}}
$$

where $y_{i}$ and $\hat{y}_{i}$ are two comparative variable values, and $\bar{y}$ is the mean of the reference variable values. In addition, the root means square error (RMSE) is the standard deviation of the residuals and is applied in the assessment of P and ET models. In this study, the mean monthly $P$ and ET series of the YRB from different models and in situ data were estimated. The coefficients of determination between two different $P$ series were calculated. Similarly, the coefficients of determination between two different ET series were calculated. After the statistical analysis of the P and ET models, we determine how to select and combine these hydrological models and then estimate runoff.

In order to estimate the trend and seasonal variation of TWSA and runoff, trend and seasonal fitted method was considered, given here as Equation (5):

$$
S=a+b \times t+c_{1} \times \cos \left(\frac{2 \pi}{T_{1}} t+\varphi_{1}\right)+c_{2} \times \cos \left(\frac{2 \pi}{T_{2}} t+\varphi_{2}\right)+\varepsilon
$$

where $S$ is the time series; $a$ and $b$ are the constant and trend terms, respectively; $c_{1}$ and $c_{2}$ are amplitude of annual and semi-annual periods, respectively; $T_{1}, T_{2}$ are annual and semi-annual periods; $t$ is the time in years; $\varphi_{1}, \varphi_{2}$ are annual and semi-annual phase; and $\varepsilon$ is the residual.

\section{Results}

\subsection{Precipitation and Evapotranspiration Variations}

Based on the spatial area mean method, we obtained four time series of $P$ over the YRB, derived from four hydrological models (CLM, NOAH, GPCP and ERA5). Then, the $R^{2}$ and RMSE between each two different hydrological models were determined to evaluate the consistency and deviation between those two models. The comparisons are shown in Figure $2 \mathrm{a}$ with red dots, and the corresponding $R^{2}$ of the six sets of compared models numbered from one to six are $0.87,0.88,0.64,0.99,0.73$ and 0.72 . Similarly, the six corresponding RMSEs are $0.08,0.07,0.21,0.06,0.18$ and 0.17 . The results show that the $R^{2}$ calculated between CLM, NOAH and GPCP was not lower than 0.87 and the RMSE did not exceed 0.08 . Conversely, the $R^{2}$ calculated using ERA5 and one other model was relatively low, and the RMSEs were larger than 0.17 . This means that three models (CLM, NOAH, GPCP) are quite consistent with each other, and that ERA5 does not exhibit good agreement with the other three models. In addition, we found that the monthly $\mathrm{P}$ amounts in ERA5 were larger than those in the other models, as shown in Figure $2 \mathrm{~b}$. The average monthly $\mathrm{P}$ amount estimated from the ERA5 $P$ model in the YRB over the period of 2003 to 2017 is $11.16 \mathrm{~cm}$. The average value derived from the other three models is $8.97 \mathrm{~cm}$, and the mean monthly $\mathrm{P}$ calculated using CMFD in-situ data is $9.35 \mathrm{~cm}$. That perhaps means that ERA5 overestimates the $\mathrm{P}$ amount, and/or that the $\mathrm{P}$ amount from the other three consistent models is underestimated. Therefore, the difference between the $\mathrm{P}$ amount estimated by ERA5 compared to the amount from the other three (combined) models provides a large uncertainty interval, which can be considered the more reliable confidence interval.

Similarly, we conducted a statistical analysis of ET data, shown in Figure 2a with blue dots. The corresponding $R^{2}$ of the six sets of compared models numbered from one to six are $0.78,0.74,0.69$, $0.94,0.88$, and 0.93 . Similarly, the six corresponding RMSEs are $0.08,0.10,0.11,0.04,0.05$, and 0.04 . This indicates that the $R^{2}$ between the CLM ET data and the other three ET data were lower than 0.78, and the RMSEs were larger than 0.08. By comparison, the $R^{2}$ values between the other three models (NOAH, GLEAM, and ERA5) were higher than 0.88, and the RMSEs were lower than 0.05 . Therefore, the mean monthly ET derived from NOAH, GLEAM, and ERA5 were compared with the monthly ET derived from CLM; see Figure 2c. The mean monthly ET amount of the YRB derived from NOAH/GLEAM/ERA5 is $6.17 \mathrm{~cm}$, and the relative underestimated mean ET amount is $5.10 \mathrm{~cm}$. However, from a previous study, the CLM ET data showed the best match with the Moderate Resolution Imaging Spectroradiometer (MODIS) satellite ET data when compared with other models in this study region (Chen YT et al., 2019), and the other models in their study, including the NOAH model. Therefore, it is not easy to determine which model is best for representing the real ET in the YRB. Some studies (Gao HL et al., 2010; Penatti et al., 2015) have emphasized that ET models tend to overestimate or underestimate the real ET in different study areas. Long D et al. (2015) suggest that ET data are particularly uncertain, making evapotranspiration the variable that may most often cause failures in water budget estimates.

Because the differences between the different models were very large, the accuracy of these models could not be well-assessed. We conclude that real $\mathrm{P}$ and ET information are difficult to determine by relying only on model results. For these reasons, in this study, we did not select one optimal model to represent the real $P$ or $E$ in the YRB. Conversely, these models provide a broader uncertainty interval, and the upper and lower limits of precipitationevapotranspiration can be determined by running and comparing all the models. The precipitation-evapotranspiration is abbreviated as P-ET in this study; the upper and lower limits of this dif- 

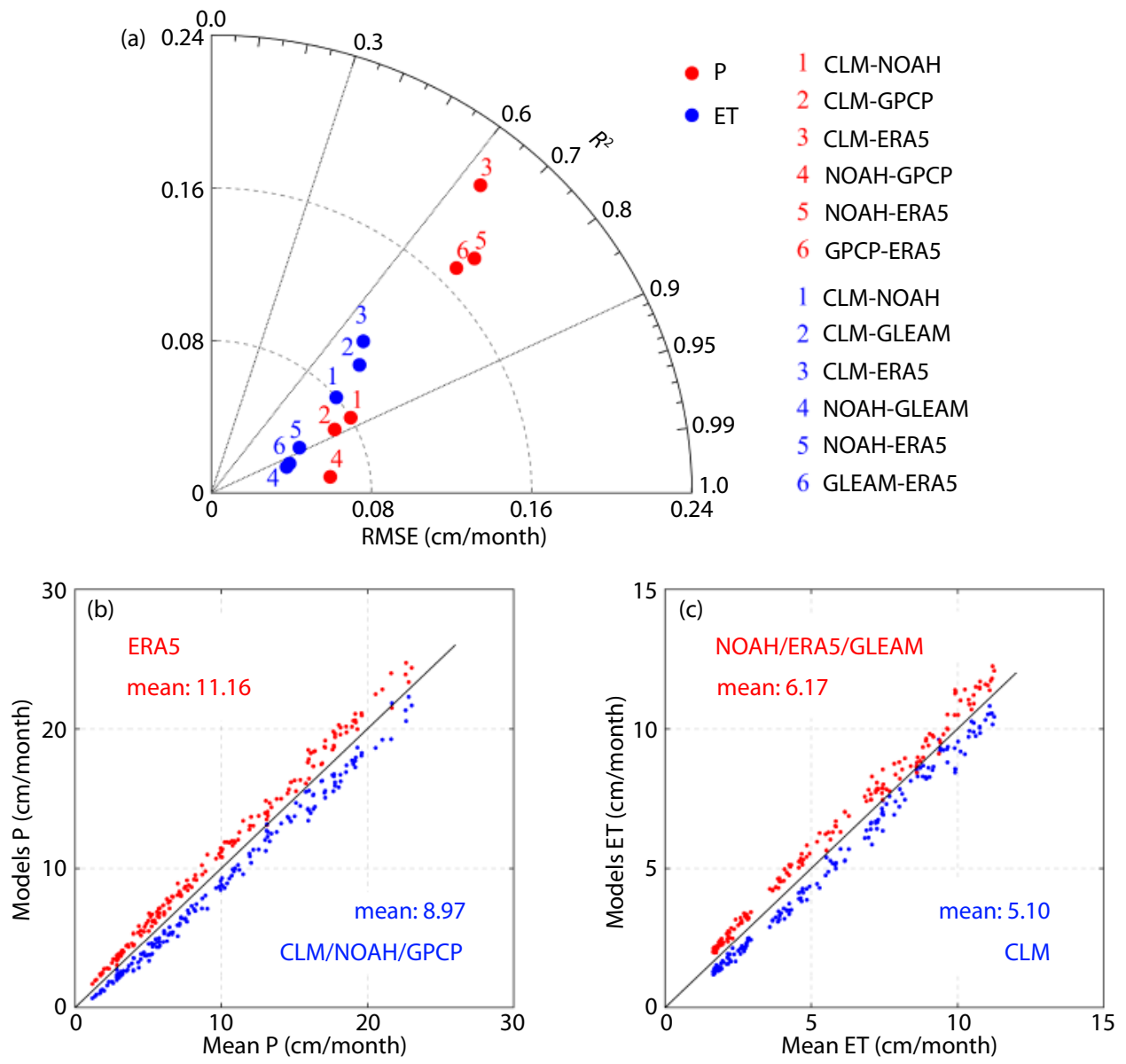

Figure 2. Statistical analysis of the P and ET models. (a) Taylor diagram showing the consistency and deviation of P and ET derived from different models; (b) the deviation between annual P derived from the ERA5 model and the other three combined models; and (c) the deviation between annual ET derived from the CLM model and the other three combined models.

ference between precipitation and evapotranspiration were determined as follows:

Upper limit: P (ERA5) minus ET (CLM).

Lower limit: P (CLM/NOAH/GPCP) minus ET (NOAH/GLEAM/ERA5). Expected values: means of the upper limit and lower limit.

For the lower limit, P (CLM/NOAH/GPCP) is relatively underestimated (compared with the in situ $\mathrm{P}$ and ERA5 models) and ET (NOAH/GLEAM/ERA5) is relatively overestimated (compared with the CLM and MODIS results), so the natural water supply derived from P (CLM/NOAH/GPCP) and E (NOAH/GLEAM/ERA5) must be underestimated, which can be considered the lower limit of the natural water supply. For the upper limit, P (ERA5) is relatively overestimated (compared with the in situ $\mathrm{P}$ and the other three $\mathrm{P}$ models), and ET (CLM) is relatively underestimated (compared with the other three models). Therefore, in this study we use these hydrological and in situ data as the basis for the confidence interval of the natural water supply data. The median values of the confidence interval were considered the expected values for the estimation of runoff, and the confidence interval was the corresponding uncertainty of the expected values.

Figure 3 shows the time series of the natural water supply and annual accumulations. The black and blue dashed lines represent the upper limit and lower limit of the natural water supply, re- spectively. The solid red line marked with red circles is the time series of P-E derived from the expected values, and the red background shadow shows the uncertainty and the confidence interval based on the hydrological models. Below the monthly series, the annual accumulated natural water supply is expressed with the blue bars, and the annual uncertainty was calculated using the root of the sum of the squared monthly uncertainties. The multiple-year averaged P-ET is $53.38 \pm 19.80 \mathrm{~cm}$, and the linear trend of the expected P-ET series is nearly zero.

Furthermore, the spatial distribution of the mean annual P-ET and corresponding uncertainty are shown in Figures $4 a$ and $4 b$, respectively. By comparison, the lower sub-basins of the YRB have larger P-ET numbers: the annual P-ET amount of the Poyang Lake sub-basin is $86.98 \mathrm{~cm}$, and the value in the Hanjiang Basin is 31.44 $\mathrm{cm}$. The model deviation is reflected mainly in the upper basins (Jinshajiang and Minjiang sub-basins). In addition, Figure 4c shows the long-term trend of the sub-basins: the maximum positive trend rate is $0.29 \mathrm{~cm} / \mathrm{yr}$ in the Poyang Lake sub-basin, the Hanjiang Basin has an average negative trend rate of $-0.07 \mathrm{~cm} / \mathrm{yr}$. The seasonal P-ET variation (Figure $4 \mathrm{~d}$ ) shows that the maximum precipitation and evapotranspiration months are June and July, respectfully; minimum precipitation and evapotranspiration occur in January and December, respectively. For the seasonal P-ET, 


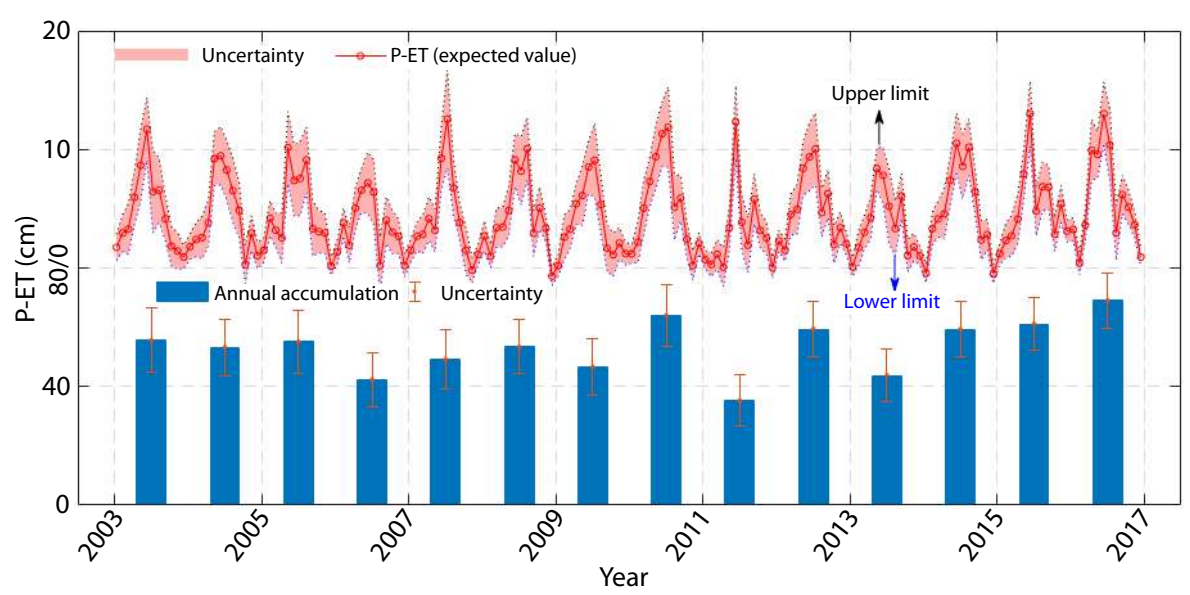

Figure 3. Time series of precipitation-evapotranspiration. The red circle solid line represents the expected values, and the black and blue dashed lines represent the bounds of the uncertainties. The bars below represent the annual natural water supply.

(a)

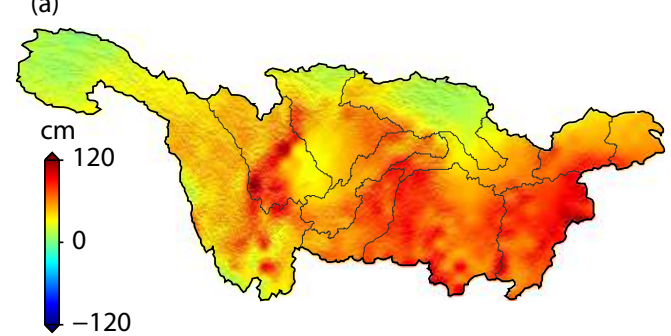

(c)

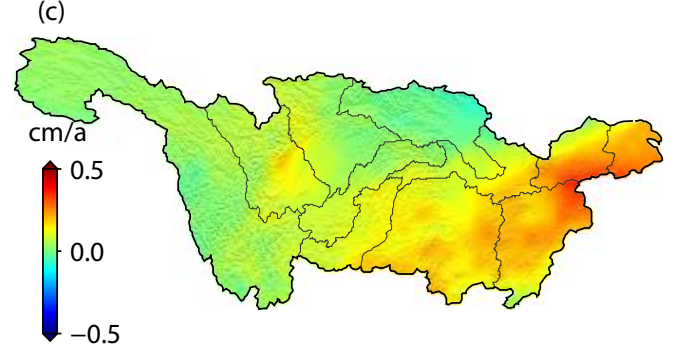

(b)
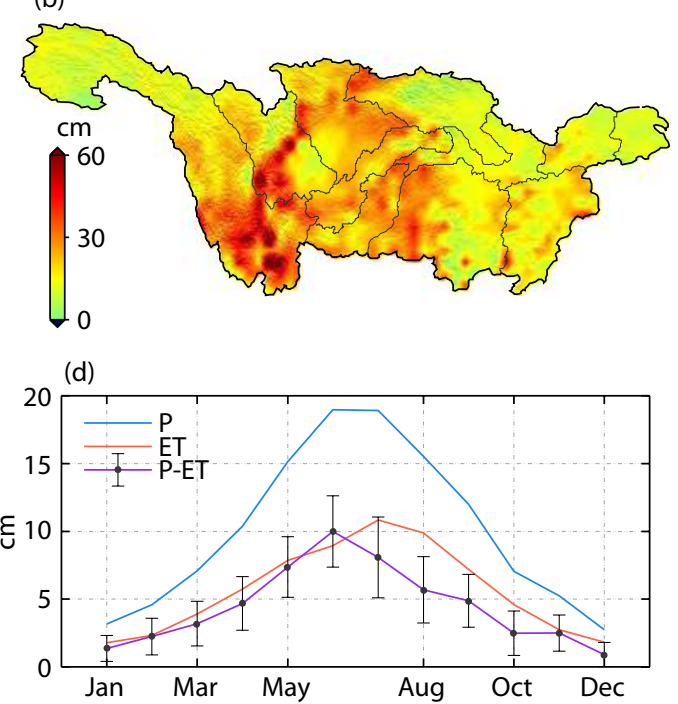

Figure 4. Spatial distribution of $P-E T$ and seasonal $P$ and ET variation. (a) Multiyear average P-ET amount; (b) uncertainty of annual P-ET amount; (c) long-term trend of P-ET; and (d) seasonal P, ET, and P-ET.

maximum water accumulation occurs in June; minimum accumulation occurs in December.

\subsection{Human Water Use and Consumption}

Human interventions are usually neglected in water budget closure. One source of human intervention is a water diversion project (e.g., the South-to-North Water Diversion (SNWD)). The watersource region of the middle reach of the SNWD project is the Hanjiang Basin (Danjiangkou Reservoir), and the water supply regions are Beijing and Tianjin (Liu $\mathrm{H}$ et al., 2018). The route line is plotted with the red line in Figure $5 \mathrm{a}$, and the inset map shows the water diversion amounts from the water source. The reported water diversion amounts in 2014, 2015, and 2016 were $0.17 \times$ $10^{9} \mathrm{~m}^{3}, 2.36 \times 10^{9} \mathrm{~m}^{3}$, and $3.77 \times 10^{9} \mathrm{~m}^{3}$, respectively. Inter-basin water transfer changed the water storage state of the YRB. As this example demonstrates, human water transfer should be included separately as an individual component in water budget closure.

In addition, the exploitation and utilization of water resources has changed terrestrial water storage conditions. For instance, the extraction of groundwater adjusts the amounts of surface and underground water. According to the Water Resources Bulletin of each province, the annual average amounts of water use and consumption from 2003 to 2016 are $150.13 \times 10^{9} \mathrm{~m}^{3}$ and $70.56 \times$ $10^{9} \mathrm{~m}^{3}$, respectively. These two values correspond to a water consumption rate of $47 \%$. Water consumption was divided into three sectors: agricultural (agriculture, forestry, animal husbandry, and fishing), industrial (mining, manufacturing, and power), and domestic (service industry, information technology, education, and living) (Wang ZM et al., 2019). The annual average water consumption for the agriculture, industry, and domestic sectors accounts roughly for $69 \%, 21 \%$, and $10 \%$, respectively, of total water consumption. Figure 5 a presents the annual mean agricultural water consumption and the industrial/municipal water consumption of each province.

More than $99.9 \%$ of the water used in agriculture is lost by crops as evapotranspiration, defined as the water loss to the air, in va- 

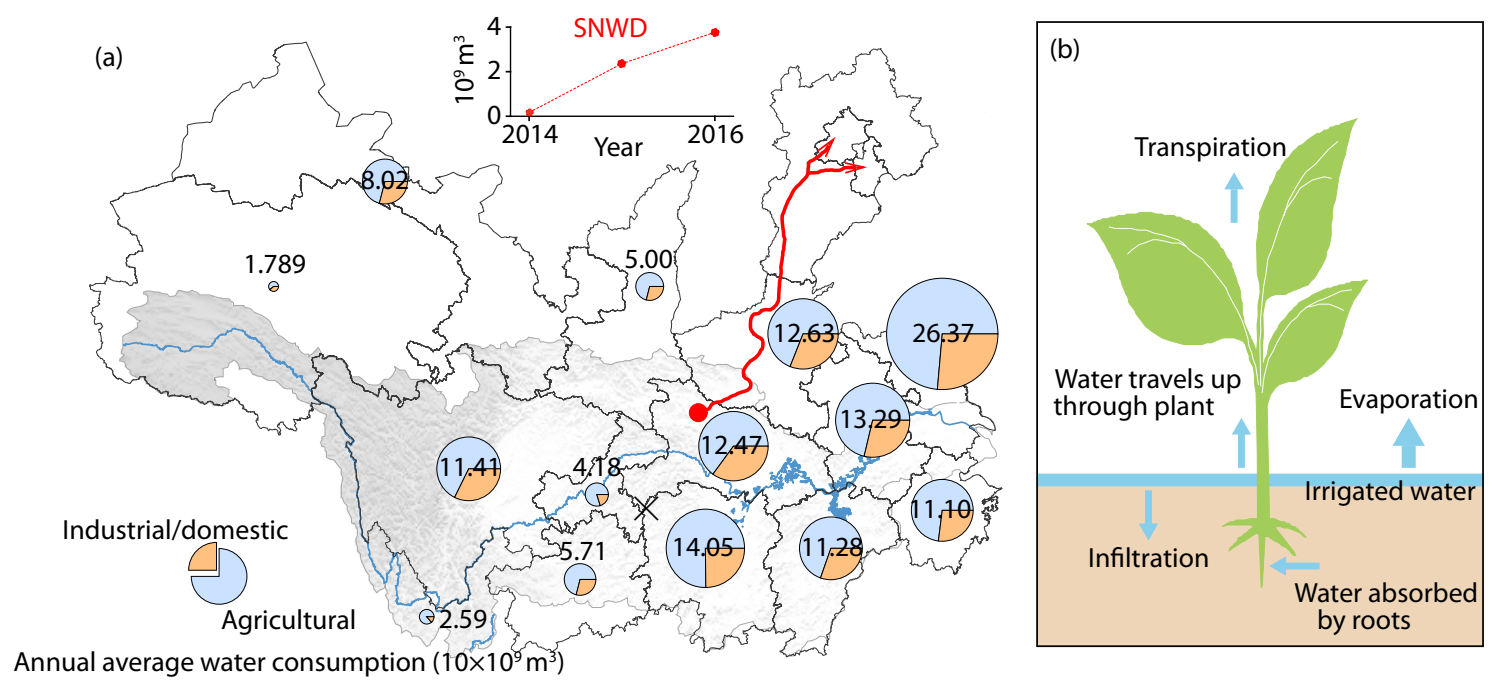

Figure 5. Human water use and consumption. (a) The average annual water consumption amount in each province; the inset graphic shows the water diversion amounts of the SNWD over the period of 2014 to 2016; (b) the plant water cycle (revised from https://byjus.com/biology/ transpiration/).

por form, by a vegetative unsaturated surface, by evaporation from soil and transpiration from plants (Rana and Katerji, 2000). Figure $5 \mathrm{~b}$ shows the plant water cycle. Only a small amount of water taken up by plants is actually used to produce plant tissue. The water use efficiency can be defined as the ratio of total biomass or grain yield to plant water consumption (Sinclair et al., 1984). The average water use efficiency of grain crops in irrigated farmland in China was $1.1 \mathrm{~kg} / \mathrm{m}^{3}$ (Duan AW and Zhang JY, 2000), and this value indicates that the mass transfer ratio of grain yield to water consumption is $0.11 \%$. Therefore, nearly all the supplied water in an irrigated area is lost via evapotranspiration. In addition, evaporation of water in industrial processing and cooling is the main form of industrial water consumption (Pham et al., 2016); domestic water disappears via direct and indirect evaporation.

Therefore, apart from inter-basin water diversion, human interventions do not affect the basin's water balance; they merely adjust the existence and condition of terrestrial water components. If a smaller spatial and time scale is considered, the effect of all human interventions can reflect small amounts of regional water transfer. In summary, water diversion realizes mass migration from the YRB to other basins, but the other modes of water consumption are restricted within the YRB. Therefore, water diversion is considered in the water budget closure equation.

\subsection{Terrestrial Water Storage Change Derived from GRACE} As introduced in Section 2.2, the forward modeling method can effectively reduce signal leakage. In this study, to distinguish the reconstructed "real" mass change value from the GRACE-observed mass change value, the ratio of the first term and the last term was calculated. Since the secular trend is not our primary focus, the monthly TWSC is more important, so the forward modeling method was applied to each monthly TWSA field observed from GRACE. The monthly optimal scale factors will be obtained when the inverted mass change field (the 'real' mass change after filtering and truncation) and the mass changes observed directly from GRACE data have the minimum relative bias. The light blue points in Figure 6a represent the factors in each published month of GRACE data. The optimal factors range from 0.91 to 1.63 (the initial range of the factors was set from 0.50 to 3.00 , and the iteration step was 0.01). The blue line with blue dots in Figure $6 \mathrm{~b}$ is the series of GRACE-observed TWSAs over the YRB, and the red dots on the red line represent the 'real' monthly TWSA after the mass recovery.

The secular GIA trend effect $(0.17 \pm 0.03 \mathrm{~cm} / \mathrm{yr}$, shown with the red line in Figure $6 c$ ) on mass change in the YRB was removed using the GIA model of Peltier et al. (2018). After the GIA correction, the TWSA series (blue line in Figure $6 \mathrm{c}$ ) had a secular trend of $0.60 \pm 0.05 \mathrm{~cm} / \mathrm{yr}$. In fact, of the 168 months of our study period, only 151 months of GRACE SHs data could be used due to unfavorable operation status of the GRACE satellite and to poor data quality. Therefore, monthly TWSCs directly estimated from the GIA-free TWSA are shown in Figure $6 \mathrm{~d}$ with light blue circles.

As GRACE monthly gravity models are often nonconsecutive, missing monthly data were interpolated from time series solutions. The first interpolated method is the series-fitted method, in which we estimated the seasonal (annual and semiannual) and linear trend terms of the GRACE TWSC series using the leastsquares fit. Therefore, the TWSC values in the missing months can be calculated using the fitted equation. The second method is the mean value method, and the missing TWSC value is replaced by the mean value of the same-month TWSC values in each year.

As introduced in Section 2.3, the series-fitted method can help us obtain from a raw series a simulated series that includes seasonal variations and trend information. Therefore, the missing month values in the raw TWSC series were replaced by those in the simulated series; the tomato-red circles in Figure $6 \mathrm{~d}$ represent the added TWSC values. In addition, the other method takes the average value of that month in other years; we show the added values with gold circles in Figure $6 \mathrm{~d}$. Based on these two methods, the annual total TWSC was calculated (as shown in Figures $6 \mathrm{e}$ and $6 \mathrm{f}$ ); the multiyear average TWSC for the first and second methods, re- 

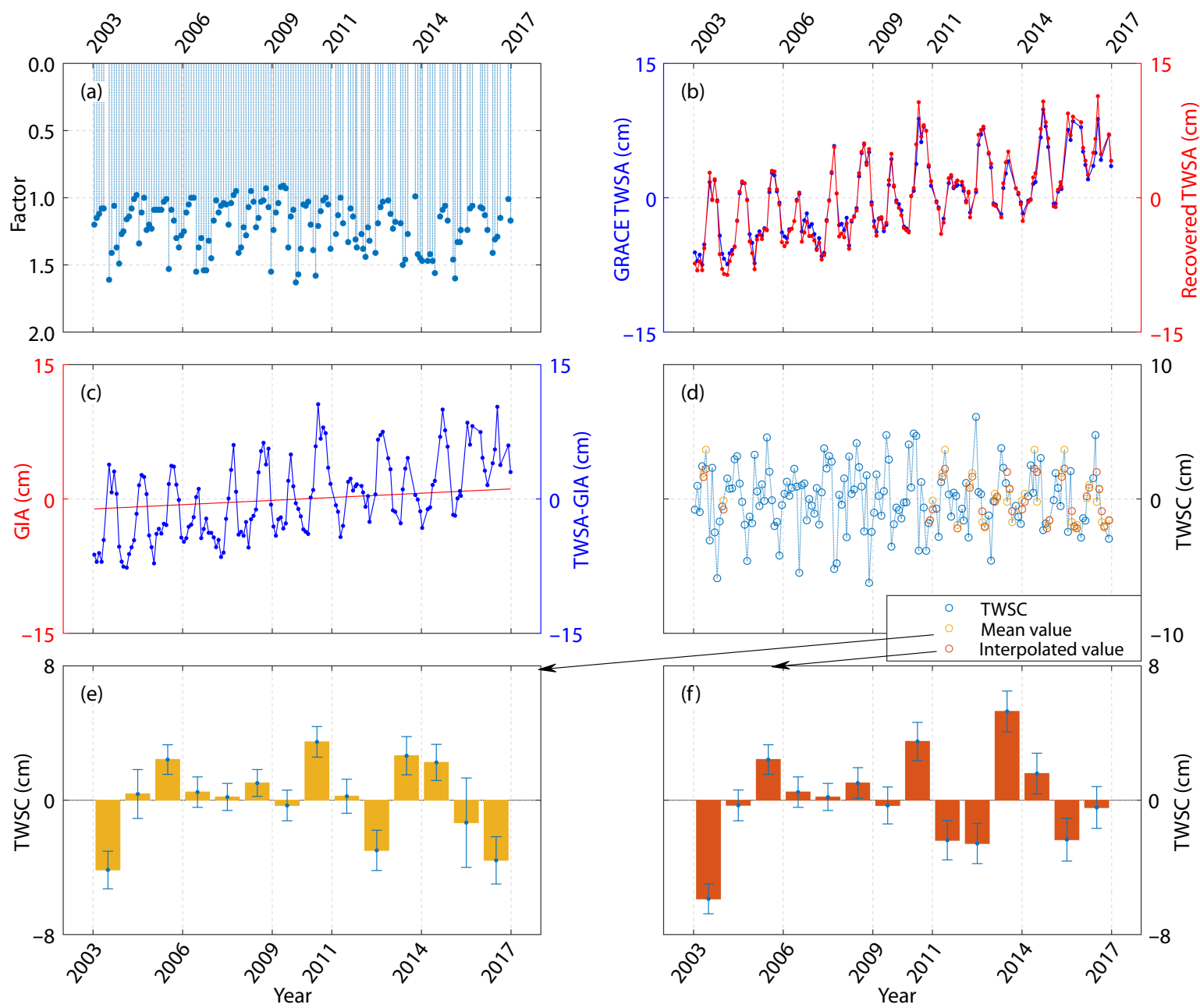

Figure 6. GRACE TWSA and TWSC of the YRB. (a) The factors of TWSA derived from the forward modeling method; (b) GRACE-observed TWSA and recovered 'real' TWSA; (c) GIA correction; (d) estimated TWSC and interpolated TWSC; (e) annual accumulated TWSC based on the mean value method; and (f) based on the series-fitted method.

spectively, are $0.05 \pm 0.33 \mathrm{~cm}$ and $0.02 \pm 0.29 \mathrm{~cm}$. The mean TWSC series of these two methods are used to estimate runoff variation over the YRB in the next section.

The spatial distribution of the multiyear average TWSC is shown in Figure 7a. The maximum positive mean yearly TWSC is in the Hanjiang Basin, with a value of $2.04 \mathrm{~cm}$; the minimum value is $-1.70 \mathrm{~cm}$, corresponding to the Poyang Lake basin. We may find that the multiyear average spatial distribution TWSC is not equal to the distribution of the TWSA trend, because the former corresponds to the mean of TWSC accumulations, while the latter is strongly related to the change mode of monthly TWSA. Based on the trend and seasonal fitted method, the seasonal and trend terms were obtained; the seasonal variation of TWSC for the entire YRB is shown in Figure 7b. The seasonal amplitude peak and valley appeared in June and October.

\subsection{Estimated Runoff Variation}

The runoff variation is obtained by deducting the TWSC and human water consumption from the P-ET, as shown in Figure 8a with the blue dashed line marked with the blue circles. We obtained a
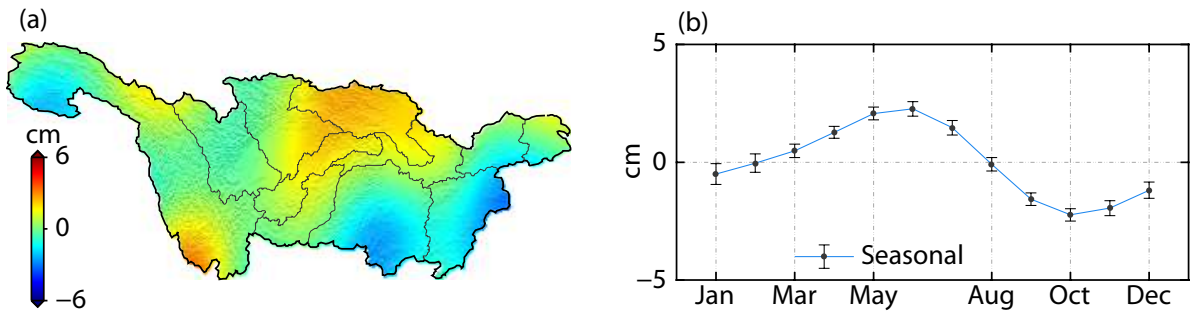

Figure 7. Multiyear average TWSC and seasonal TWSC. (a) The spatial distribution of the multiyear average TWSC over the YRB; and (b) the seasonal TWSC derived from the two methods. 

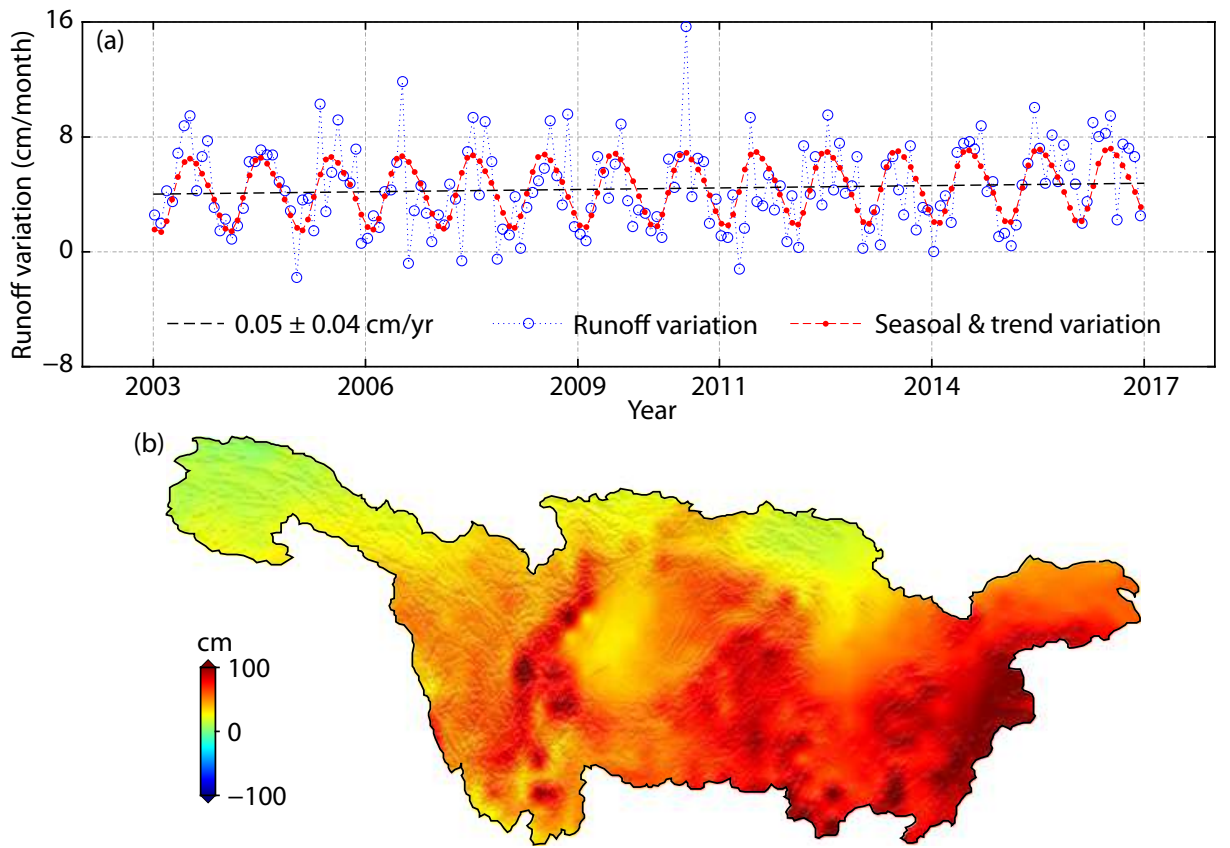

Figure 8. Estimated runoff variation in the YRB. (a) Estimates and uncertainties of monthly runoff, and seasonal, trend runoff variations, and (b) the spatial distribution of multiyear average runoff.

multiyear average runoff rate of $53.34 \pm 22.51 \mathrm{~cm}$ for the YRB; the runoff series for the YRB was accompanied by a slightly increasing trend of $0.05 \pm 0.04 \mathrm{~cm} / \mathrm{yr}$ (black dashed line). In addition, the red line in Figure $8 \mathrm{a}$ is the seasonal and trend variation runoff. For the entire YRB, we estimate the correlation coefficient between P-E and runoff to be 0.72 , and the correlation coefficient between TWSC and runoff to be 0.50 .

To discuss seasonal runoff variation in the YRB, the year was divided into pre-monsoon, post-monsoon, monsoon, summer, and winter seasons; their corresponding months are summarized in Table 1. During the monsoon season, the mean monthly runoff amount is $6.51 \pm 1.46 \mathrm{~cm} / \mathrm{month}$, the monsoon season showing a slight upward trend of $0.04 \mathrm{~cm} / \mathrm{month} /$ year over the study period. In addition, the mean TWSC in this season is $0.65 \pm 0.29$ $\mathrm{cm} /$ month, accounting for only $10 \%$ of runoff. This means that the rate of terrestrial water accumulation in the monsoon season is small compared with P-ET and runoff. In addition, Table 1 summarizes the monthly mean runoff, runoff variation, and monthly mean TWSC. The maximum monthly mean runoff takes place in summer, when the rate of $6.52 \mathrm{~cm} /$ month is slightly larger than that in the monsoon season. The minimum monthly mean runoff takes place in winter, not more than one-third of the runoff amount in summer; during winter, the monthly runoff shows an upward trend of $0.07 \mathrm{~cm} / \mathrm{month} / \mathrm{yr}$. In addition, a significant increase in runoff appears in the pre-monsoon and post-monsoon seasons, when the runoff variation is determined nearly completely by P-ET. By comparison, runoff has the opposite variation as P-ET in the summer and winter seasons because TWSC has a consistent variation with $\mathrm{P}-\mathrm{ET}$, and a more intense TWSC variation adjusted the runoff state. Furthermore, on the one hand, the positive and negative values $(1.40 \pm 0.30 \mathrm{~cm} /$ month and $-0.48 \pm 0.33$ $\mathrm{cm} /$ month) of TWSC reflect seasonal terrestrial water accumulation and loss characteristics. On the other hand, the variation in TWSC shows that the terrestrial water accumulation in the summer and the water loss in the winter were both accelerating.

The spatial distribution of multiyear runoff of the YRB is shown in Figure $8 b$. The mean annual runoff amounts of the Jinshajiang, Minjiang, Jialingjiang, Hanjiang, Upstream, Wujiang, Dongting Lake, Midstream, Downstream, Poyang Lake, and Delta Plain subbasins, respectively, are $39.57 \pm 9.34 \mathrm{~cm}, 50.07 \pm 10.25 \mathrm{~cm}, 40.54 \pm$

Table 1. Seasonal runoff variations and trends.

\begin{tabular}{|c|c|c|c|c|c|c|}
\hline Season & Months & Mean $R(\mathrm{~cm})$ & $R$ variation $(\mathrm{cm} / \mathrm{yr})$ & P-ET variation $(\mathrm{cm} / \mathrm{yr})$ & TWSC (cm) & TWSC variation $(\mathrm{cm} / \mathrm{yr})$ \\
\hline Pre-Monsoon & $3-5$ & $4.09 \pm 1.14$ & $\uparrow(0.08)$ & $\uparrow(0.07)$ & $0.99 \pm 0.27$ & 0.00 \\
\hline Post-Monsoon & $10-12$ & $3.86 \pm 0.77$ & $\uparrow(0.09)$ & $\uparrow(0.10)$ & $-1.89 \pm 0.31$ & $\uparrow(0.01)$ \\
\hline Monsoon & $6-9$ & $6.51 \pm 1.46$ & $\uparrow(0.04)$ & $\uparrow(0.09)$ & $0.65 \pm 0.29$ & $\uparrow(0.05)$ \\
\hline Summer & $6-8$ & $6.52 \pm 1.56$ & $\downarrow(-0.01)$ & $\uparrow(0.03)$ & $1.40 \pm 0.30$ & $\uparrow(0.04)$ \\
\hline Winter & $12-2$ & $1.98 \pm 0.88$ & $\uparrow(0.07)$ & $\downarrow(-0.09)$ & $-0.48 \pm 0.33$ & $\downarrow(-0.11)$ \\
\hline
\end{tabular}

Note: the unit of $\mathrm{cm}$ means the average monthly amount, and $\mathrm{cm} / \mathrm{yr}$ represents the trend. 
$10.00 \mathrm{~cm}, 29.37 \pm 8.96 \mathrm{~cm}, 54.57 \pm 11.18 \mathrm{~cm}, 64.07 \pm 12.65 \mathrm{~cm}$ $73.43 \pm 13.25 \mathrm{~cm}, 54.27 \pm 12.92 \mathrm{~cm}, 65.90 \pm 12.15 \mathrm{~cm}, 88.38 \pm$ $14.68 \mathrm{~cm}$, and $61.26 \pm 9.97 \mathrm{~cm}$. The Poyang Lake basin experienced the highest mean monthly runoff amount; the runoff trend at that location was positive: $7.37 \mathrm{~cm}$ and $0.34 \mathrm{~cm} / \mathrm{yr}$, respectfully. In contrast, the lowest mean monthly runoff amount and a clear negative trend $(2.12 \mathrm{~cm}$ and $-0.08 \mathrm{~cm} / \mathrm{yr}$, respectfully) were observed at Hanjiang Basin. Among the remaining stations, the lower sub-basins (Dongting Lake, Downstream, and Delta Plain) recorded relatively large runoff amounts and more significant runoff increases.

When runoff was used to estimate the total water flux in the sub-basins and compared with the hydrological observed discharge flux volume, we found that the total water flux of most sub-basins was very close to the observed discharge volume at the corresponding hydrological control station. The orange column in Figure 9a represents the estimated mean annual runoff amount in each sub-basin and the confluence amount; the blue column represents the in situ river discharge measured at the corresponding station. The river flux measured at mainstream stations was the total flux of all upstream sub-basins; the discharge amount at the Chenglingji station represents the net water output amount of the Dongting Lake basin because we deducted the water amount of the four input tributaries of that basin. Figure $9 \mathrm{~b}$ shows the annual discharge series at each hydrological station; the orange dot with an error bar represents the estimated yearly runoff amount, and blue dots are the in situ measured surface runoff amounts. During the uncertainty intervals, the estimated mean annual runoff amounts for most of the hydrological stations were very close to the observations at the hydrological stations. For the Hanjiang Basin, the effect of the SNWD has been reflected in the basin runoff since 2014. In fact, human water resource diversion can be considered one example of runoff. This was included in the hydrological station measurements of this study, as shown with the red dots. The contribution of human water diversion accounts for only only $8 \%$ of the observed runoff at the Huangzhuang station.

\section{Discussion and Conclusions}

For the entire YRB, the mean annual runoff amount is $53.34 \pm$ $22.51 \mathrm{~cm}$, and the mean annual surface discharge amount from the hydrological station is $858 \times 10^{9} \mathrm{~m}^{3}$, equivalent to annual surface runoff of $47.65 \mathrm{~cm}$. On the one hand, because the subsurface runoff is not clearly distinguished from surface river discharge, we can estimate the subsurface runoff based on the estimates and observations. On the other hand, when in situ data are considered, we will be able to assess the effects of applying the hydrological model.

Within the uncertainty of estimated runoff variations, the annual mean subsurface runoff interval is between $-16.82 \mathrm{~cm}$ and $28.20 \mathrm{~cm}$, and the ratios of subsurface runoff to surface runoff range from $-55 \%$ to $37 \%$. For the Yangtze tributary sub-basins,
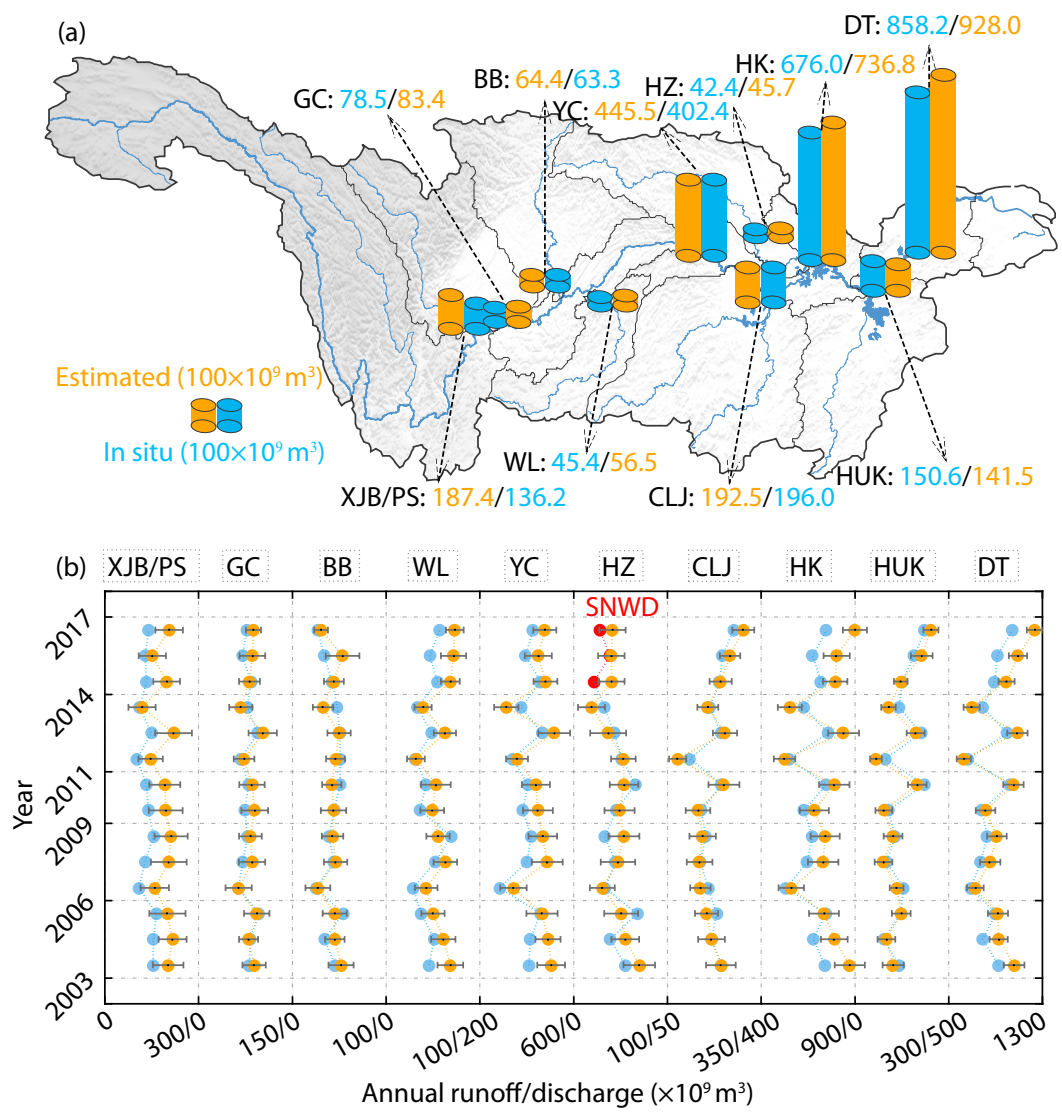

Figure 9. Comparison between annual river discharge and estimated basin runoff volume. (a) Estimated mean annual runoff amount and in situ discharge volume; and (b) annual runoff and discharge series of the sub-basins. 
the subsurface $R$ was calculated directly, by deducting the subsurface $R$ from the estimated total $R$. The yearly subsurface $R$ amounts in these sub-basins ranged from $-5.69 \mathrm{~cm}$ to $12.60 \mathrm{~cm}$, and the ratios of subsurface $R$ to total $R$ ranged from $-37 \%$ to $41 \%$. For the mainstream Yangtze River, the subsurface $R$ measured at a station represents the merged amount of all upper tributaries. Therefore, the net surface $R$ amount of the mainstream basin was calculated by deducting all upper tributaries' contributions from the mainstream station measurements. Naturally, corresponding uncertainties were considered in estimating subsurface $R$ of the mainstream basin. Finally, the estimated ratios of subsurface $R$ to total $R$ range from $-145 \%$ to $73 \%$ for the mainstream sub-basins. Despite the very large uncertainty intervals of the subsurface runoff estimates, these intervals restrict the range of possible results under this wide range of actual subsurface runoff.

The uncertainties of the estimates in this study come mainly from limitations of the hydrological model. ET has been deemed "one of the most uncertain variables that may cause failures of water budget estimates of TWSC" (Long D et al., 2015). As shown in Section 3.1, P-ET was divided mainly into two parts, relative underestimation and overestimation. Typically, consistency between models can be used as a reference for selecting an optimum model. That is, the CLM/NOAH/GPCP P model and the NOAH/GLEAM/ ERA5 ET model may be most suitable for representing the real $P$ and ET in the YRB. However, this combined model corresponds to the lower limits of P-ET, and the estimated total runoff accounts for only $65 \%$ of the surface station observations. The best interpretation is that the hydrological models have strongly underestimated the runoff. Therefore, we have applied a more conservative approach to determining the uncertainty interval or the broader confidence interval in this study. Based on the CMFD data, the estimated monthly mean precipitation amount is 9.35 $\mathrm{cm}$, which is closer to the value given by the CLM/NOAH/GPCP $P$ model than by the ERA5 $\mathrm{P}$ model, suggesting that the ERA5 $\mathrm{P}$ model almost certainly overestimates real $P$, and, further, that the ET also is considerably overestimated.

The Datong station is at the tidal limit of the estuary (Ferreira et al., 2013); due to the tidal effect, it is not possible to measure the discharge from a station at the mouth of the YRB. In this study, the Datong station, whose actual control area is $94 \%$ of the total area of the YRB, was considered the control station for the whole YRB. In fact, the net discharge variation in the delta plain is difficult to measure due to the limit of water storage capacity and the effect of seawater recharging. Therefore, the discharge variation measured at the Datong station is typically considered the total discharge of the YRB. In this study, in situ measured data were used as the reference for surface runoff. Actually, the uncertainty of the in situ data should be considered further.

From the above results, a precise value of how much subsurface $R$ contributes to the total $R$ of the YRB is still difficult to determine due to the large uncertainty interval. However, the large ratio between the subsurface runoff and total runoff inferred indirectly from related results suggests that the real subsurface runoff is closer to the upper limit of the estimated subsurface runoff. In other words, the estimated subsurface runoff from the P-ET mod- el has been underestimated. In fact, we suggest that the runoff balance method is the best method to estimate subsurface runoff if the surface hydrological data are sufficiently accurate.

In this study, monthly and annual runoff variations in the YRB and sub-basins were estimated based on the water closure equation. The broader confidence interval of the estimated runoff was determined in this study. Within this confidence interval, the total runoff, surface runoff, and subsurface discharge were well balanced.

The main conclusions in this study are summarized as follows:

(1) The annual average runoff, surface discharge, and subsurface runoff of the YRB are $53.34 \pm 22.51 \mathrm{~cm}, 47.65 \mathrm{~cm}$, and $5.69 \pm 22.51$ $\mathrm{cm}$, respectively, and the contribution of subsurface runoff estimated from the water budget balance to total runoff ranges from $-55 \%$ to $\sim 37 \%$.

(2) Runoff increases exist in the YRB and most sub-basins, especially in the pre- and post-monsoon seasons and in the lower subbasins; terrestrial water storage accumulation occurs primarily in the pre-monsoon and summer seasons, and terrestrial water storage loss occurs mainly in the post-monsoon and winter seasons.

(3) The contribution of human water consumption is finally reflected in evapotranspiration, and the effect of the SNWD on the subbasin of the YRB accounts for $8 \%$ of runoff.

(4) The mainstream hydrological models still almost certainly underestimate or overestimate precipitation and evapotranspiration in the YRB; in particular, our analysis suggests overestimation by the evapotranspiration models.

\section{Acknowledgments}

We would like to thank the anonymous reviewers for their valuable suggestions and instructions. This research was supported by the National Natural Science Foundation of China (41974093, 41774088, 41331066 and 42174097) and the Key Research Project of Frontier Bureau of Chinese Academy of Sciences (qyzdy-sswsys003). In addition, we would like to thank the providers of scientific data used in this paper.

The GLDAS precipitation, evapotranspiration and runoff data can be accessed at https://ldas.gsfc.nasa.gov/gldas/.

GRACE data is available at (http://icgem.gfz-potsdam.de/).

The precipitation data from GPCP v2.3 is available at https://psl. noaa.gov/data/gridded/data.gpcp.html.

ERA5 land datasets can be found at https://www.ecmwf.int/en/ forecasts/datasets/reanalysis-datasets/era5).

GLEAM evapotranspiration data is available at https://www.gleam. eu/.

The CMDF can be found at National Tibetan Plateau Third Pole Environment Data Center http://data.tpdc.ac.cn/.

\section{References}

Adler, R. F., Huffman, G. J., Chang, A., Ferraro, R., Xie, P. P., Janowiak, J., Rudolf, B., Schneider, U., Curtis, S., ... Nelkin, E. (2003). The version-2 global precipitation climatology project (GPCP) monthly precipitation analysis (1979-Present). J. Hydrometeorol., 4(6), 1147-1167.

https://doi.org/10.1175/1525-7541(2003)004<1147:TVGPCP>2.0.CO;2

Adler, R. F., Sapiano, M. R. P., Huffman, G. J., Wang, J. J., Gu, G. J., Bolvin, D., Chiu, 
L., Schneider, U., Becker, A., ... Shin, D. B. (2018). The global precipitation climatology project (GPCP) monthly analysis (New Version 2.3) and a review of 2017 global precipitation. Atmosphere, 9(4), 138. https://doi.org/10.3390/atmos 9040138

Anderson, R. G., Lo, M. H., Swenson, S., Famiglietti, J. S., Tang, Q., Skaggs, T. H., Lin, Y. H., and Wu, R. J. (2015). Using satellite-based estimates of evapotranspiration and groundwater changes to determine anthropogenic water fluxes in land surface models. Geosci. Model Dev., 8(10), 3021-3031. https://doi.org/10.5194/gmd-8-3021-2015

Chang, L., and Sun, W. K. (2021). Progress and prospect of sea level changes of global and China nearby seas. Rev. Geophys. Planet. Phys. (in Chinese), 52(3), 266-279. https://doi.org/10.19975/j.dqyxx.2020-028

Chen, J. L., Li, J., Zhang, Z. Z., and Ni, S. N. (2014). Long-term groundwater variations in Northwest India from satellite gravity measurements. Global Planet.Change, 116, 130-138. https://doi.org/10.1016/j.gloplacha.2014.02.007

Chen, J. L., Famigliett, J. S., Scanlon, B. R., and Rodell, M. (2016). Groundwater storage changes: present status from GRACE observations. Surv. Geophys., 37(2), 397-417. https://doi.org/10.1007/s10712-015-9332-4

Chen, J. L., Tapley, B., Rodell, M., Seo, K. W., Wilson, C., Scanlon, B. R., and Pokhrel, Y. (2020). Basin-scale river runoff estimation from GRACE gravity satellites, climate models, and in situ observations: a case study in the Amazon Basin. Water Resour. Res., 56(10), e2020WR028032. https://doi.org/10.1029/2020WR028032

Chen, Y. T., Fok, H. S., Ma, Z. T., and Tenzer, R. (2019). Improved remotely sensed total basin discharge and its seasonal error characterization in the Yangtze River Basin. Sensors, 19(15), 3386. https://doi.org/10.3390/s19153386

Cheng, M., and Ries, J. (2017). The unexpected signal in GRACE estimates of $C_{20}$. J. Geod., 91(8), 897-914. https://doi.org/10.1007/s00190-016-0995-5

Duan, A. W., and Zhang, J. Y. (2000). Water use efficiency of grain crops in irrigated farmland in China. Trans. Chin. Soc. Agric. Eng. (in Chinese), 16(4), 41-44. https://doi.org/10.3321/j.issn:1002-6819.2000.04.011

Famiglietti, J. S., Ryu, D., Berg, A. A., Rodell, M., and Jackson, T. J. (2008). Field observations of soil moisture variability across scales. Water Resour. Res., 44(1), W01423. https://doi.org/10.1029/2006WR005804

Fang, J., He, M. L., Luan, W., and Jiao, J. S. (2021). Crustal vertical deformation of Amazon Basin derived from GPS and GRACE/GFO data over past two decades. Geod. Geodyn., 12(6), 441-450. https://doi.org/10.1016/j.geog.2021.09.002

Ferreira, V. G., Gong, Z., He, X. F., Zhang, Y. L., and Andam-Akorful, S. A. (2013). Estimating total discharge in the Yangtze River Basin using satellite-based observations. Remote Sens., 5(7), 3415-3430. https://doi.org/10.3390/rs5073415

Gao, H. L., Tang, Q. H., Ferguson, C. R., Wood, E. F., and Lettenmaier, D. P. (2010). Estimating the water budget of major US river basins via remote sensing. Int. J. Remote Sens., 31(14), 3955-3978. https://doi.org/10.1080/01431161.2010.483488

He, J., Yang, K., Tang, W. J., Lu, H., Qin, J., Chen, Y. Y., and Li, X. (2020). The first high-resolution meteorological forcing dataset for land process studies over China. Sci. Data, 7(1), 25. https://doi.org/10.1038/s41597-020-0369-y

Hersbach, H., Bell, B., Berrisford, P., Hirahara, S., Horányi, A., Muñoz-Sabater, J., Nicolas, J., Peubey, C., Radu, R., ... Thépaut, J. N. (2020). The ERA5 global reanalysis. Quart. J. Royal Meteor. Soc., 146(730), 1999-2049. https://doi.org/10.1002/qj.3803

Huang, Y., Salama, M. S., Krol, M. S., Van Der Velde, R., Hoekstra, A. Y., Zhou, Y., and Su, Z. (2013). Analysis of long-term terrestrial water storage variations in the Yangtze River basin. Hydrol. Earth Syst. Sci., 17(5), 1985-2000. https://doi.org/10.5194/hess-17-1985-2013

Jing, W. L., Yao, L., Zhao, X. D., Zhang, P. Y., Liu, Y. X. Y., Xia, X. L., Song, J., Yang, J., Li, Y., and Zhou, C. H. (2019). Understanding terrestrial water storage declining trends in the Yellow River Basin. J. Geophys. Res.: Atmos., 124(23), 12963-12984. https://doi.org/10.1029/2019JD031432

Li, Q., Luo, Z. C., Zhong, B., and Zhou, H. (2018). An improved approach for evapotranspiration estimation using water balance equation: case study of Yangtze River Basin. Water, 10(6), 812. https://doi.org/10.3390/w10060812

Liu, H., Yin, J., and Feng, L. (2018). The dynamic changes in the storage of the
Danjiangkou reservoir and the influence of the south-north water transfer project. Sci. Rep., 8(1), 8710. https://doi.org/10.1038/s41598-018-26788-5

Long, D., Longuevergne, L., and Scanlon, B. R. (2014). Uncertainty in evapotranspiration from land surface modeling, remote sensing, and GRACE satellites. Water Resour. Res., 50(2), 1131-1151.

https://doi.org/10.1002/2013WR014581

Long, D., Yang, Y. T., Wada, Y., Hong, Y., Liang, W., Chen, Y. N., Yong, B., Hou, A. Z., Wei, J. F., and Chen, L. (2015). Deriving scaling factors using a global hydrological model to restore GRACE total water storage changes for China's Yangtze River Basin. Remote Sens. Environ., 168, 177-193. https://doi.org/10.1016/j.rse.2015.07.003

Lv, M. X., Hao, Z. C., Lin, Z. H., Ma, Z. G., Lv, M. Z., and Wang, J. H. (2016). Reservoir operation with feedback in a coupled land surface and hydrologic model: a case study of the Huai River Basin, China. JAWRA J. Amer. Water Resour. Assoc., 52(1), 168-183. https://doi.org/10.1111/1752-1688.12375

Lv, M. X., Ma, Z. G., Yuan, X., Lv, M. Z., Li, M. X., and Zheng, Z. Y. (2017). Water budget closure based on GRACE measurements and reconstructed evapotranspiration using GLDAS and water use data for two large denselypopulated mid-latitude basins. J. Hydrol., 547, 585-599. https://doi.org/10.1016/j.jhydrol.2017.02.027

Lv, M. X., Ma, Z. G., Li, M. X., and Zheng, Z. Y. (2019). Quantitative analysis of terrestrial water storage changes under the grain for green program in the Yellow River Basin. J. Geophys. Res.: Atmos., 124(3), 1336-1351. https://doi.org/10.1029/2018JD029113

Lv, M. Z., Yang, Z. L., Xu, Z. F., Dan, L., Lv, M. X., and Zheng, H. (2021). A soil moisture-dependent model to simulate water table depth and proportions of surface and subsurface runoff and its validation at the basin scale. J. Geophys. Res.: Atmos., 126(4), e2020JD033661. https://doi.org/10.1029/2020JD033661

Martens, B., Miralles, D. G., Lievens, H., Van Der Schalie, R., De Jeu, R. A. M., Fernández-Prieto, D., Beck, H. E., Dorigo, W. A., and Verhoest, N. E. C. (2017). GLEAM v3: satellite-based land evaporation and root-zone soil moisture. Geosci. Model Dev., 10(5), 1903-1925. https://doi.org/10.5194/gmd-101903-2017

Martin, G. M., Dunstone, N. J., Scaife, A. A., and Bett, P. E. (2020). Predicting June mean rainfall in the middle/lower Yangtze River basin. Adv. Atmos. Sci, 37(1), 29-41. https://doi.org/10.1007/s00376-019-9051-8

Niu, G. Y., Yang, Z. L., Mitchell, K. E., Chen, F., Ek, M. B., Barlage, M., Kumar, A., Manning, K., Niyogi, D., ... Xia, Y. L. (2011). The community Noah land surface model with multiparameterization options (Noah-MP): 1. Model description and evaluation with local-scale measurements. J. Geophys. Res.: Atmos., 116(D12), D12109. https://doi.org/10.1029/2010JD015139

Oliveira, P. T. S., Nearing, M. A., Moran, M. S., Goodrich, D. C., Wendland, E., and Gupta, H. V. (2014). Trends in water balance components across the Brazilian Cerrado. Water Resour. Res., 50(9), 7100-7114. https://doi.org/10.1002/2013WR015202

Peltier, W. R., Argus, D. F., and Drummond, R. (2018). Comment on "an assessment of the ICE-6G_C (VM5a) glacial isostatic adjustment model" by Purcell et al. J. Geophys. Res.: Solid Earth, 123(2), 2019-2028. https://doi.org/10.1002/2016JB013844.

Penatti, N. C., De Almeida, T. I. R., Ferreira, L. G., Arantes, A. E., and Coe, M. T. (2015). Satellite-based hydrological dynamics of the world's largest continuous wetland. Remote Sens. Environ., 170, 1-13. https://doi.org/10.1016/j.rse.2015.08.031

Pham, T. T., Mai, T. D., Pham, T. D., Hoang, M. T., Nguyen, M. K., and Pham, T. T. (2016). Industrial water mass balance as a tool for water management in industrial parks. Water Resour. Ind., 13, 14-21. https://doi.org/10.1016/j.wri.2016.04.001

Rana, G., and Katerji, N. (2000). Measurement and estimation of actual evapotranspiration in the field under Mediterranean climate: a review. Eur. J. Agron., 13(2-3), 125-153. https://doi.org/10.1016/S1161-0301(00)00070-8

Rao, W. L., and Sun, W. K. (2021). Moho interface changes beneath the Tibetan Plateau based on GRACE data. J. Geophys. Res.: Solid Earth, 126(2), e2020JB020605.

Rao, W. L., and Sun, W. K. (2022). Uplift of the Tibetan Plateau: how to accurately compute the hydrological load effect. J. Geophys. Res.: Solid Earth, 127(1), 
e2021JB022475. https://doi.org/10.1029/2021JB022475

Rodell, M., and Famiglietti, J. S. (1999). Detectability of variations in continental water storage from satellite observations of the time dependent gravity field. Water Resour. Res., 35(9), 2705-2723. https://doi.org/10.1029/1999WR900141

Rodell, M., Houser, P. R., Jambor, U., Gottschalck, J., Mitchell, K., Meng, C. J., Arsenault, K., Cosgrove, B., Radakovich, J., ... Toll, D. (2004). The global land data assimilation system. Bull. Amer. Meteor. Soc., 85(3), 381-394. https://doi.org/10.1175/BAMS-85-3-381

Shen, Y., Wang, Q. Y., Rao, W. L., and Sun, W. K. (2022). Spatial distribution characteristics and mechanism of nonhydrological time-variable gravity in China contient. Earth Planet. Phys., 6(1), 96-107. https://doi.org/10.26464/epp2022009

Sichangi, A. W., Wang, L., Yang, K., Chen, D. L., Wang, Z. J., Li, X. P., Zhou, J., Liu, W. B., and Kuria, D. (2016). Estimating continental river basin discharges using multiple remote sensing data sets. Remote Sens. Environ., 179, 36-53. https://doi.org/10.1016/j.rse.2016.03.019

Sinclair, T. R., Tanner, C. B., and Bennett, J. M. (1984). Water-use efficiency in crop production. BioScience, 34(1), 36-40. https://doi.org/10.2307/1309424

Sun, Q. H., Miao, C. Y., Duan, Q. Y., Ashouri, H., Sorooshian, S., and Hsu, K. L. (2018). A review of global precipitation data sets: data sources, estimation, and intercomparisons. Rev. Geophys., 56(1), 79-107. https://doi.org/10.1002/2017RG000574

Sun, Y., Riva, R., and Ditmar, P. (2016). Optimizing estimates of annual variations and trends in geocenter motion and $J_{2}$ from a combination of GRACE data and geophysical models. J. Geophys. Res.: Solid Earth, 121(11), 8352-8370. https://doi.org/10.1002/2016JB013073

Swenson, S., Chambers, D., and Wahr, J. (2008). Estimating geocenter variations from a combination of GRACE and ocean model output. J. Geophys. Res.: Solid Earth, 113(B8), B08410. https://doi.org/10.1029/2007JB005338

Syed, T. H., Famiglietti, J. S., Chen, J., Rodell, M., Seneviratne, S. I., Viterbo, P., and Wilson, C. R. (2005). Total basin discharge for the Amazon and Mississippi River basins from GRACE and a land-atmosphere water balance. Geophys. Res. Lett., 32(24), L24404. https://doi.org/10.1029/2005GL024851

Syed, T. H., Famiglietti, J. S., and Chambers, D. P. (2009). GRACE-based estimates of terrestrial freshwater discharge from basin to continental scales. J. Hydrometeorol., 10(1), 22-40. https://doi.org/10.1175/2008JHM993.1
Wang, G. J., Jiang, T., Blender, R., and Fraedrich, K. (2008). Yangtze 1/f discharge variability and the interacting river-lake system. J. Hydrol., 351(1-2), 230-237. https://doi.org/10.1016/j.jhydrol.2007.12.016

Wang, H. S., Xiang, L. W., Steffen, H., Wu, P., Jiang, L. M., Shen, Q., Li, Z., and Hayashi, M. (2022). GRACE-based estimates of groundwater variations over North America from 2002 to 2017. Geod. Geodyn., 13(1), 11-23. https://doi.org/10.1016/j.geog.2021.10.003

Wang, Z. M., Nguyen, T., and Westerhoff, P. (2019). Food-energy-water analysis at spatial scales for districts in the Yangtze River Basin (China). Environ. Eng. Sci., 36(7), 789-797. https://doi.org/10.1089/ees.2018.0456

Xing, L. L., Liu, Z. W., Jia, J. G., Wu, S. Q., Chen, Z. S., and Niu, X. W. (2021). Farfield coseismic gravity changes related to the $2015 M_{\mathrm{w}} 7.8$ Nepal (Gorkha) earthquake observed by superconducting gravimeters in mainland China. Earth Planet. Phys., 5(2), 141-148. https://doi.org/10.26464/epp2021018

Xu, X. F., Li, X. L., Wang, X. J., He, C. S., Tian, W., Tian, J., and Yang, L. X. (2020). Estimating daily evapotranspiration in the agricultural-pastoral ecotone in Northwest China: a comparative analysis of the Complementary Relationship, WRF-CLM4.0, and WRF-Noah methods. Sci. Total Environ., 729, 138635. https://doi.org/10.1016/j.scitotenv.2020.138635

Xue, B. L., Wang, L., Li, X. P., Yang, K., Chen, D. L., and Sun, L. T. (2013). Evaluation of evapotranspiration estimates for two river basins on the Tibetan Plateau by a water balance method. J. Hydrol., 492, 290-297. https://doi.org/10.1016/j.jhydrol.2013.04.005

Zhang, D., Zhang, Q., Werner, A. D., and Liu, X. M. (2016). GRACE-based hydrological drought evaluation of the Yangtze River basin, China. J. Hydrometeorol., 17(3), 811-828. https://doi.org/10.1175/JHM-D-15-0084.1

Zhang, J., Van Heyden, J., Bendel, D., and Barthel, R. (2011). Combination of soilwater balance models and water-table fluctuation methods for evaluation and improvement of groundwater recharge calculations. Hydrogeol. J., 19(8), 1487-1502. https://doi.org/10.1007/s10040-011-0772-8

Zhang, L., and Sun, W. K. (2022). Progress and prospect of GRACE Mascon product and its application. Rev. Geophys. Planet. Phys. (in Chinese), 53(1), 35-52. https://doi.org/10.19975/j.dqyxx.2021-033

Zhu, M., Zhang, Z. X., Zhu, B., Kong, R., Zhang, F. Y., Tian, J. X., and Jiang, T. (2020). Population and economic projections in the Yangtze River basin based on shared socioeconomic pathways. Sustainability, 12(10), 4202. https://doi.org/10.3390/su12104202 